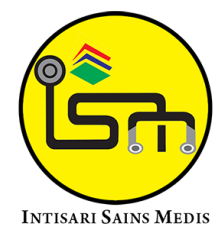

Published by Intisari Sains Medis

\section{Diagnosa dan Tatalaksana pada Hemoroid Derajat IV: Laporan Kasus}

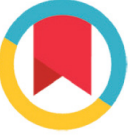

CrossMark

\author{
Ni Nyoman Amik Indrayani ${ }^{1 *}$, Agung Aditya Arnaya ${ }^{1}$, \\ Kevin Kristanto Wiguna', Ida Bagus Putu Wiyasa ${ }^{2}$
}

${ }^{1}$ Dokter Magang di SMF Bedah RSUD Wangaya ${ }^{2}$ Dokter Spesialis Bedah di SMF Bedah RSUD Wangaya
*Korespondensi:

Ni Nyoman Amik Indrayani;

Dokter Magang di SMF Bedah RSUD Wangaya;

amik.indrayani@gmail.com

\section{ABSTRACT}

Background : Hemorrhoids affect millions of people around the world and become one of the main medical and socioeconomic problems Hemorrhoids are symptomatic widening of the hemorrhoidal plexus and distal displacement of the normal cushion. This case report aims to discuss cases of hemorrhoids from diagnosis to management.

Case Report: A30-year-old male came with complaints of fresh blood discharge during defecation. Complaints have been felt for 1 month ago and have worsened for 1 day before being admitted to the hospital. On local examination in the anal region, there was a mass with an irregular shape around the anal, some of which were blackish red in color and partly the same color as the surrounding skin with a diameter of $3 \mathrm{~cm}$. On palpation, the mass was palpable, firm, tenderness, the mass could not be given with a finger. Based on the history and physical examination, the patient was diagnosed with grade IV internal hemorrhoids and an open hemorrhoidectomy (Miligan-Morgan method) was planned.

Conclusion: The diagnosis of hemorrhoids is obtained from the patient's medical history, physical examination and supporting examinations. Therapeutic management of hemorrhoids can be in the form of animation and surgery.
Keywords: Hemorrrhoid, mass, hemorrhoidectomy

Cite This Article: Indrayani, N.N.A., Arnaya, A.A., Wiguna, K.K., Wiyasa, I.B.P. 2021. Diagnosa dan Tatalaksana pada Hemoroid Derajat IV: Laporan Kasus. Intisari Sains Medis 12(3): 706-709. D0I: 10.15562/ism.v12i3.1165

\section{ABSTRAK}

Latar Belakang: Hemoroid mengenai jutaan orang diseluruh dunia dan menjadi salah satu masalah medis utama dan masalah sosioekonomi Hemoroid adalah pelebaran simptomatis dari pleksus hemoroid dan pergeseran bantalan anus ke arah distal dari normal. Laporan kasus ini bertujuan untuk membahas kasus hemoroid dari diagnosa sampai dengan tatalaksananya. Laporan Kasus: Seorang laki-laki usia 30 tahun datang dengan keluhan keluar darah berwarna merah segar saat buang air besar. Keluhan dirasakan sejak 1 bulan yang lalu dan memberat sejak 1 hari sebelum masuk rumah sakit. Pada pemeriksaan lokalis di regio anal terlihat adanya benjolan dengan bentuk iregular mengitari anus yang sebagian berwarna merah kehitaman dan sebagian sama dengan warna kulit disekitarnya dengan ukuran diameter $3 \mathrm{~cm}$. Saat dilakukan palpasi didapatkan benjolan teraba kenyal, batas tegas, nyeri tekan (+) benjolan tidak dapat dimasukkan dengan jari. Berdasarkan dari anamnesa dan pemeriksaan fisik, pasien kemudian didiagnosa dengan Hemorroid interna grade IV dan ditangani dengan metode open hemorrhoidectomy (MiliganMorgan Method). Pasien dirawat selama dua hari dimana pasien sudah bisa buang air besar tetapi masih terasa nyeri namun benjolan sudah tidak terlihat dari anus.

Simpulan: Hemoroid dapat didiagnosa dari riwayat medis pasien, pemeriksaan fisik serta pemeriksaan penunjang. Manajemen terapi pada hemoroid dapat berupa konservatif dan operasi. 


\section{PENDAHULUAN}

Plekus hemoroidalis adalah suatu jaringan normal yang terdapat pada semua orang, yang terdiri atas pleksus arteri-vena, berfungsi sebagai katup di dalam saluran anus untuk membantu sistem sfingter anus, mencegah inkontinensia flatus dan cairan. Pelebaran yang simptomatis dari pleksus hemoroid dan pergeseran bantalan anus ke arah distal dari normal merupakan pengertian dari hemoroid. ${ }^{1,2}$

Hemoroid mengenai jutaan orang diseluruh dunia dan menjadi salah satu masalah medis utama dan masalah sosioekonomi. Menurut data WHO, jumlah penderita hemoroid di dunia pada tahun 2008 mencapai lebih dari 230 juta jiwa. Menurut data Depkes tahun 2007, penderita hemoroid di Indonesia mencapai 5,7 \% tetapi hanya $1,5 \%$ pasien hemoroid yang terdiagnosa. Hemoroid lebih sering dijumpai pada penduduk yang berusia lebih dari 25 tahun. Hemoroid dapat menimbulkan kondisi tidak nyaman pada penderita. ${ }^{2,3}$

Hemoroid derajat 4 merupakan kategori hemoroid yang paling parah dengan penanganan yang kompleks. ${ }^{1}$ Tidak banyak kasus hemoroid derajat IV yang ditemukan di lapangan, namun luaran terapi dari kondisi ini sangat bervariasi. Oleh karena itu, pada laporan kasus ini dipresentasikan satu kasus berupa penanganan medis hemoroid derajat IV serta luaran terapinya.

\section{LAPORAN KASUS}

Seorang laki-laki usia 30 tahun datang ke Unit Gawat Darurat Rumah Sakit Umum Daerah Wangaya dengan keluhan keluar darah segar saat buang air besar. Keluhan dirasakan sejak 1 bulan yang lalu tetapi sejak 1 hari sebelum ke UGD, darah yang keluar sangat banyak dan pasien merasa lemas. Sejak 15 tahun yang lalu pasien merasa ada benjolan yang keluar saat pasien $\mathrm{BAB}$ ataupun mengejan tetapi benjolan tersebut masih bisa masuk kembali ke dalam anus. Kemudian sejak 3 bulan yang lalu, benjolan tidak bisa masuk kembali ke anus. Awalnya benjolan terlihat kecil dan semakin lama semakin membesar. Pasien mengeluh nyeri saat buang air besar. Nyeri hanya terasa saat buang air besar dan nyeri hilang jika pasien sudah selesai buang air besar. Tidak didapatkan penurunan berat badan ataupun penurunan nafsu makan.

Pasien sebelumnya tidak pernah memiliki sakit seperti ini. Selain itu pasien juga tidak memiliki riwayat penyakit kronis seperti diabetes mellitus, hipertensi, ataupun kanker. Keluarga pasien juga tidak memliki riwayat penyakit seperti ini. Pasien tidak menyukai makan makanan berserat seperti buah dan sayur. Pasien juga memiliki kebiasaan mengejan jika buang air besar. Pasien belum pernah operasi sebelumnya.

Pasien datang ke UGD dalam keadaan sadar. Pada saat dilakukan pemeriksaan fisik didapatkan tekanan darah 110/70 mmHg, nadi 86 kali per menit, laju pernapasan 18 kali per menit, dan suhu $36,7^{\circ} \mathrm{C}$. Tidak didapatkan anemis pada konjungtiva. Pemeriksaan thorak dan abdomen tidak didapatkan kelainan. Pada pemeriksaan lokalis di regio anal terlihat adanya benjolan dengan bentuk iregular mengitari anus yang sebagian berwarna

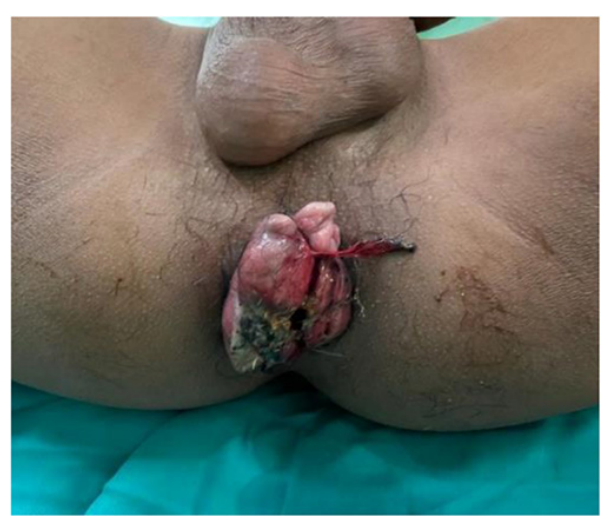

Gambar 1. Hemoroid Internal derajat IV Sumber: dokumentasi pribadi

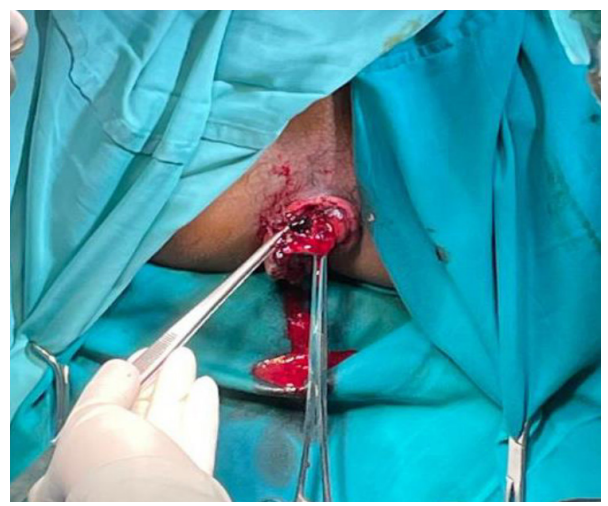

Gambar 2. Gambar 2. Dilakukan insisi berpola $\mathrm{V}$

Sumber: dokumentasi pribadi merah kehitaman dan sebagian sama dengan warna kulit disekitarnya dengan ukuran diameter $3 \mathrm{~cm}$ (Gambar 1). Saat dilakukan palpasi didapatkan benjolan teraba kenyal, batas tegas, nyeri tekan $(+)$ benjolan tidak dapat dimasukkan dengan jari.

Berdasarkan dari anamnesa dan pemeriksaan fisik, pasien kemudian didiagnosa dengan Hemorroid interna derajat IV dan direncanakan dilakukan open hemorrhoidectomy (MiliganMorgan Method) (Gambar 2 dan 3). Sebelum dilakukan tindakan tersebut, dilakukan persiapan dengan pemeriksaan darah lengkap, masa perdarahan, masa pembekuan, fungsi hati dan ginjal serta gula darah sewaktu. Tidak didapatkan kelainan dari pemeriksaan tersebut sehingga pasien dapat dilakukan operasi.

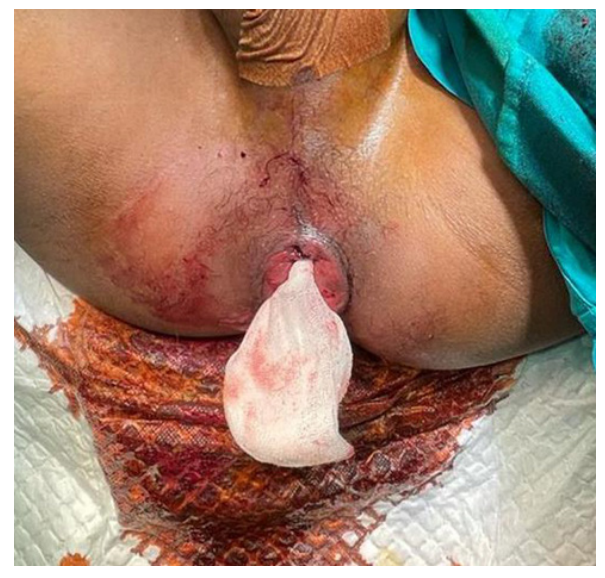

Gambar 3. Gambar 3. Dipasang tampon setelah dilakukan open hemorrhoidectomy Sumber: dokumentasi pribadi

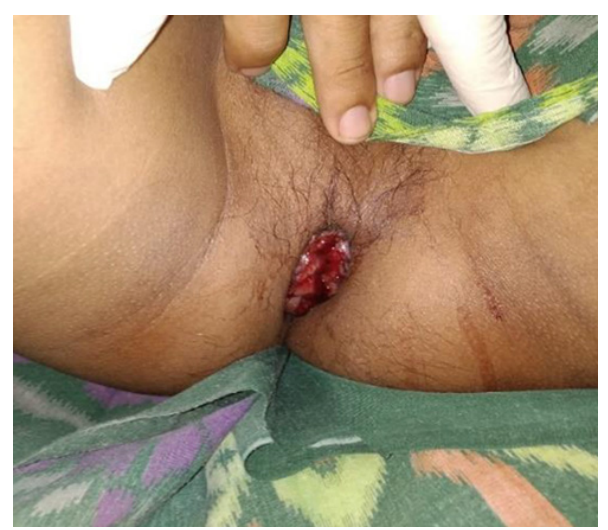

Gambar 4. Gambar 4. Area anus satu hari pasca operasi Sumber: dokumentasi pribadi 
Setelah dilakukan open hemorrhoidectomy (Miligan-Morgan Method), pasien dirawat selama dua hari dimana pasien sudah bisa buang air besar tetapi masih terasa nyeri saat buang air besar. Benjolan sudah tidak terlihat dari anus (Gambar 4).

\section{PEMBAHASAN}

Menurut lokasinya hemoroid dibedakan menjadi dua yaitu hemoroid interna dan hemoroid eksterna. Hemoroid interna adalah adalah pleksus vena hemoroidalis superior di atas garis mukokutan dan ditutupi oleh mukosa. Hemoroid interna merupakan bantalan vascular di dalam jaringan submukosa pada rektum sebelah bawah. Hemoroid sering dijumpai pada tiga posisi primer, yaitu kanandepan, kanan-belakang, dan kiri lateral. Hemoroid yang lebih kecil terdapat di antara ketiga letak primer tersebut..,2

Hemoroid eksterna yang merupakan pelebaran dan penonjoan pleksus hemoroid inferior terdapat di sebelah distal garis mukokutan di dalam jaringan dibawah epitel anus. Kedua pleksus hemoroid, internus dan eksternus, saling berhubungan secara longgar dan merupakan awal dari aliran vena yang kembali bermula dari rektum sebelah bawah dan anus. Pleksus hemoroid internus mengalirkan darah ke vena hemoroidalis superior dan selanjutnya ke vena porta. Pleksus hemoroid eksternus mengalirkan darah ke peredaran darah sistemik melalui daerah perineum dan lipat paha ke vena iliaka. ${ }^{1,2}$

Berbagai macam faktor disebutkan sebagai penyebab hemoroid. Beberapa faktor tersebut antara lain konstipasi, mengejan terlalu lama, kehamilan, dan obesitas. Feses yang keras dan

\section{Tabel 1. Klasifikasi Hemoroid Interna}

I Perdarahan pada bantalan anus tetapi tidak terjadi prolaps

II Terjadi prolaps pada hemoroid interna selama defekasi, dan dapat kembali spontan.

III Terjadi prolaps pada hemoroid interna selama defekasi, dan harus dikembalikan secara manual

IV Terjadi prolaps pada hemoroid interna dan tidak dapat dimasukkan kembali. peningkatan tekanan intraabdominal dapat menyebabkan obstruksi dari venous return, sehingga terjadi pembengkakan pleksus hemoroid. Kehamilan dapat menyebabkan kongesti dari bantalan anus dan hemoroid simtomatik, dan akan kembali normal secara spontan segera setelah melahirkan. Mengejan yang lama saat buang air besar dapat memicu perkembangan gejala seperti keluar darah atau munculnya benjolan saat buang air besar. Faktor diet seperti diet rendah serat, makanan pedas, dan alkohol telah berimplikasi terhadap terjadinya hemoroid, tetapi data yang dilaporkan masih inkonsisten. ${ }^{4,5}$

Diagnosis hemoroid adalah bersifat klinis yang dimulai dari riwayat penyakit pasien terutama yang mengarah ke hemoroid seperti Cardinal sign dari hemoroid interna yakni perdarahan berwarna merah segar tanpa disertai rasa nyeri dan diikuti dengan keluarnya benjolan saat mengejan. Benjolan dapat kembali spontan ataupun dengan cara manual. Jika sudah terjadi hemoroid interna derajat IV, maka benjolan tidak dapat kembali masuk ke dalam anus. ${ }^{6}$

Pemeriksaan fisik dapat dilakukan dalam posisi prone, knee-chest, atau lateral decubitus. Posisi tersebut harus dapat memberikan visual yang baik saat dilakukan inspeksi anus. Selain itu juga harus memberikan kenyamanan saat dilakukan pemeriksaan colok dubur (rectal toucher) untuk evaluasi kelainan pada anus dan otot sphincter. Pemeriksaan anoskopik dapat dilakukan untuk menilai dari anatomi anus. ${ }^{6,7}$

Pemeriksaaan penunjang dapat memastikan bahwa gejala yag muncul bukan disebabkan oleh penyebab lain selain hemoroid seperti polip ataupun keganasan kolorektal. Pemeriksaan penunjang seperti pemeriksaan darah samar pada feses (fecal occult blood test) untuk melihat adanya kandungan darah pada feses. Pemeriksaan lain untuk menilai kolon secara keseluruhan seperti kolonoskopi, sigmoidoskopi, dan barium enema. ${ }^{6,7}$

Pemeriksaan kolon secara keseluruhan diindikasikan pada pasien dengan kriteria yang disebutkan pada table berikut ${ }^{6}$

1. Usia $\geq 50$ tahun jika tidak dilakukan pemeriksaan secara lengkap dalam 10 tahun terakhir.

2. Usia $\geq 40$ tahun 10 tahun lebih muda dari usianya saat didiagnosis dengan riwayat positif untuk diri sendiri, kerabat tingkat pertama dengan kanker kolorektal, atau adenoma tingkat lanjut yang didiagnosa pada usia $<60$ tahun.

3. Usia $\geq 40$ tahun 10 tahun lebih muda dari usianya saat didiagnosis dengan riwayat positif untuk dua orang kerabat tingkat pertama dengan kanker kolorektal, atau adenoma tingkat lanjut

4. Positif pada fecal immunochemical testing (FIT)

5. Positif pada FIT-fecal DNA test

Sumber: Davis, R.B., et al. 2018

Manajemen terapi pada hemoroid dapat berupa konservatif dan operasi. Manajemen konservatif yaitu modifikasi gaya hidup, medikasi peroral dan medikasi topikal. Sebagian besar pasien hemoroid internal derajat I dan II serta beberapa pasien derajat III yang gagal dengan manajemen konservatif dapat diterapi secara lebih efektif dengan office-based procedures seperti rubber band ligation, skleroterapi, dan infrared coagulation, cryosurgery, manual anal dilatation (Lord's procedure), LASER hemorrhoidectomy, the harmonic ultrasonic scalpel hemorrhoidectomy, atomizing hemorrhoids, doppler-guided hemorrhoidal artery ligation. Tujuan dari office-based procedures adalah untuk meringankan gejala pasien dengan mengurangi ukuran atau vaskularisasi dari jaringan hemoroid dan untuk meningkatkan fiksasi jaringan hemoroid ke dinding rektum untuk meminimalkan prolaps. ${ }^{6-8}$

Metode operasi atau hemoroidektomi dapat dilakukan pada pasien dengan gejala yang dihasilkan oleh hemoroid

Sumber : Lohsiriwat, W. 2012 
eksterna atau kombinasi hemoroid interna dan eksterna dengan prolaps (derajat III-IV). Beberapa jenis metode operasi pada hemoroid antara lain diathermy hemorrhoidectomy, LigaSure and Starion hemorrhoidectomy, semi closed hemorrhoidectomy, submucosal hemorrhoidectomy (Park's Procedure), Farag's Procedure (Farag, 1978), anopexy, stapled hemorrhoidectomy,

clamp and cautery hemorrhoidectomy, open hemorrhoidectomy (Milligan Morgan Method), closed hemorrhoidectomy (Ferguson's Method), whitehead's circumferential hemorrhoidectomy. ${ }^{7,8}$

Pada kasus ini digunakan open hemorrhoidectomy (Miligan-Morgan Method). Ini adalah prosedur yang paling sering digunakan dan umumnya dipandang sebagai teknik bedah terbaik untuk mengobati hemoroid. Pada tahun 1937 metode ini digambarkan oleh Dr. Milligan dan Dr. Morgan di Inggris, untuk mengobati hemoroid derajat 2 sampai derajat IV. Potongan berpola $\mathrm{V}$ dibuat dipangkal hemoroid sampai jaringan hemoroid lengkap dideseksi dari bantalanya. Deseksi dilakukan dari kranial sampai pedikel yang kemudian diikat dengan benang catgut yang kuat dan bagian distal diekstraksi. Jaringan yang tersisa juga dihilangkan dengan cara yang sama, meninggalkan kulit bagian tengah untuk menghindari stenosis. Sayatan dibiarkan terbuka dan untuk menghentikan pendarahan (perban hemostatik) disimpan di saluran anus. Metode ini menyebabkan rasa sakit yang parah, waktu penyembuhan luka yang lama, dan komplikasi seperti stenosis anal. ${ }^{8-10}$

\section{SIMPULAN}

Hemoroid adalah pelebaran yang simptomatis dari pleksus hemoroidalis dan pergeseran bantalan anus ke arah distal dari normal. Hemoroid dibagi menjadi dua yaitu hemoroid interna dan hemoroid eksterna. Diagnosa hemoroid diperoleh dari riwayat medis pasien, pemeriksaan fisik serta pemeriksaan penunjang. Manajemen terapi pada hemoroid dapat berupa konservatif dan operasi

\section{KONFLIK KEPENTINGAN}

Penulis menyatakan tidak terdapat konflik kepentingan terkait publikasi dari laporan kasus ini.

\section{PERSETUJUAN ETIK}

Pasien telah menyetujui digunakannya data-data medis untuk penyusunan artikel ini. Formulir ICJME juga telah disertakan saat submisi artikel ini.

\section{PENDANAAN}

Penelitian ini tidak mendapatkan suatu pendanaan yang diberikan oleh pemerintah atau lembaga swasta lainnya.

\section{KONTRIBUSI PENULIS}

Masing-masing penulis berkontribusi yang sama dalam penulisan laporan kasus ini.

\section{DAFTAR PUSTAKA}

1. Sjamsuhidajat, R. Buku Ajar Ilmu Bedah Sjamsuhidajat-de Jong. Jakarta: Penerbit ECG. 2010. Page 788-792

2. Lohsiriwat, W. Hemorrhoids: From basic pathophysiology to clinical management. World Journal of Gastroenterology 2012; 18(17): 20092017.

3. Yusmanedi, Mandala,Z. Faktor Risiko Kejadian Hemoroid pada Supir Bus AKAP di Pool PO. Gumarang Jaya. Jurnal Medika Malahayati 2014; 1(4): 147-151.

4. Brown, S. R. Haemorrhoids: an update on management. Therapeutic Advances in Chronic Disease 2017; 8(10):141-147

5. Sun, Z., Migaly, J. Review of Hemorrhoid Disease: Presentation and Management. Clinics in Colon and Rectal Surgery 2016; 29 (1): 22-29

6. Ganz, R.A. The evaluation and treatment of hemorrhoids: A Guide for the gastroenterologist. Clinical Gastroenterology and Hepatology 2013; 11: 593-603.

7. Davis, R.B., et al. The American Society of Colon and Rectal Surgeons Clinical Practice Guidelines for the Management of Hemorrhoids. Disease of The Colon and Rectum 2018: 61(3). Page 284-292.

8. Gupta, S. et al. Review Article Recent Management Of Hemorrhoids: A Pharmacological \& Surgical Perspective. Plant Archives. 2020; 20(1): 3828-3837

9. Agbo, S.P. Surgical Management of Hemorrhoids. Journal of Surgical Technique and Case Report. 2011; 3(2): 68-75.

10. Lu,M.etal.Milligan-Morganhemorrhoidectomy with anal cushion suspension and partial internal sphincter resection for circumferential mixed hemorrhoids. World Journal of Gastroenterology. 2013: 19(30). 5011-5015

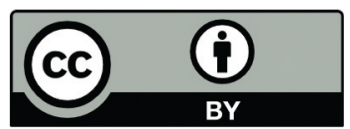

This work is licensed under a Creative Commons Attribution 